\title{
POTENCIAL DE ÁGUA DO SOLO E ADUBAÇÃO COM BORO NO CRESCIMENTO E ABSORÇÃO DO NUTRIENTE PELA CULTURA DA SOJA ${ }^{(1)}$
}

\author{
Ricardo Robson Trautmann ${ }^{(2)}$, Maria do Carmo Lana ${ }^{(3)}$, Vandeir Francisco Guimarães ${ }^{(4)}$, \\ Affonso Celso Gonçalves Jr. ${ }^{(4)}$ \& Fabio Steiner ${ }^{(5)}$
}

\begin{abstract}
RESUMO
A soja é uma cultura exigente em boro (B), entretanto, é estreita a faixa entre o nível adequado e o tóxico para esse nutriente no solo; dessa forma, a dose a ser recomendada deve ser bem definida. As condições hídricas do solo também é um aspecto importante relacionado diretamente com a disponibilidade de B para as plantas. Nesse contexto, este trabalho teve como objetivo avaliar o efeito da aplicação de fontes e doses de B no crescimento da soja (Glycine max) em um Latossolo Vermelho eutroférrico de textura arenosa, submetido a diferentes tensões de água. $O$ experimento foi conduzido em casa de vegetação em vasos com $5 \mathrm{dm}^{3}$ de solo. Utilizou-se o delineamento experimental em parcelas subdivididas, em esquema fatorial $5 \times 2 \times 3$, sendo cinco doses de $B\left(0,0 ; 0,25 ; 0,5 ; 1,0 ;\right.$ e $\left.2,0 \mathrm{mg} \mathrm{dm}^{-3}\right)$; duas fontes (ácido bórico e colemanita) e três tensões de água no solo $(0,01 ; 0,03 ;$ e $0,10 \mathrm{MPa}$ ), com quatro repetições. Os resultados indicaram que o crescimento da soja não é influenciado quando se mantém o nível de tensão de água no solo até $0,1 \mathrm{MPa}$. $\mathrm{O}$ crescimento do sistema radicular foi interferido negativamente com a aplicação de doses de $B$ até $2 \mathrm{mg} \mathrm{dm}^{-3}$, em solo com teor inicial de $0,32 \mathrm{mg} \mathrm{dm}^{-3}$. Os teores de $\mathrm{B}$ no solo e no tecido foliar da soja aumentaram linearmente com as doses do nutriente aplicado no solo, sendo observado na maior dose $\left(2 \mathrm{mg} \mathrm{dm}^{-3} \mathrm{de} \mathrm{B}\right)$ sintomas de típicos de toxidez de B nas folhas da cultura da soja.
\end{abstract}

Termos de indexação: Glycine max, micronutriente, tensão de agua.

(1) Parte da Dissertação de Mestrado do primeiro autor apresentada ao Programa de Pós-Graduação em Produção Vegetal da Universidade Estadual do Oeste do Paraná - UNIOESTE. Recebido para publicação em 16 de agosto de 2012 e aprovado em 25 de setembro de 2013.

(2) Engenheiro-Agrônomo, Mestre em Agronomia. E-mail: trautmann_agronomo@hotmail.com

(3) Professora Associada, Centro de Ciências Agrárias - CCA/UNIOESTE, Campus de Marechal Cândido Rondon. Rua Pernambuco, 1777. CEP 859600-000 Marechal Cândido Rondon (PR), Brasil. Bolsista CNPq. E-mail: maria.lana@unioeste.br

(4) Professor Associado, Centro de Ciências Agrárias - CCA/UNIOESTE. Bolsista do CNPq. E-mail: vandeirfg@yahooo.com.br, affonso133@hotmail.com

(5) Professor, Departamento de Agronomia, Faculdade Integradas de Ourinho - FIO. Rod. BR 153, km 338,4. CEP 18909-100 Ourinhos (SP). E-mail: fsteiner.agro@yahoo.com.br 


\title{
SUMMARY: SOIL WATER POTENCIAL AND BORON FERTILIZATION IN GROWTH AND UPTAKE OF THE NUTRIENT FOR THE SOYBEAN CROP
}

\begin{abstract}
Soybean is one of the annual crops most demanding of boron (B); however, borate fertilizer should be managed cautiously, especially in regard to application rates, because of the narrow range between the appropriate level and toxic level for this nutrient in the soil. Another important factor directly related to B availability to plants refers to soil water conditions. In this context, this study evaluated the effect of sources and application rates of B on soybean growth (Glycine max) in a Latossolo Vermelho (Oxisol) with a sandy texture, subjected to different water tensions. The experiment was conducted in greenhouse in pots with $5 \mathrm{dm}^{3}$ of soil. We used a split plot experimental design in a $5 \times 2 \times 3$ factorial arrangement with five application rates of $B(0.0$, $0.25,0.5,1.0$ and $2.0 \mathrm{mg} \mathrm{dm}^{-3}$ ), two B sources (boric acid and colemanite) and three soil water tensions $(0.01,0.03$ and $0.10 \mathrm{MPa})$, with four replications. The results indicated that soybean growth is not affected when the level of soil water tension is maintained up to-0.1 MPa. Root system growth was adversely affected by B application rates of up to $2 \mathrm{mg} \mathrm{dm}^{-3}$ in soil with an initial level of $0.32 \mathrm{mg} \mathrm{dm}^{-3}$. The levels of $B$ in the soil and in leaf tissue of soybean increase linearly with nutrient application rates in the soil, and typical symptoms of $B$ toxicity in soybean leaves were observed at the highest rate $\left(2 \mathrm{mg} \mathrm{dm}^{-3}\right.$ of $\left.B\right)$.
\end{abstract}

Index terms: Glycine max, micronutrient, water tension.

\section{INTRODUÇÃO}

Atualmente, o Brasil se destaca no cenário mundial como segundo maior produtor e exportador de grãos de soja. Nos últimos anos, a soja também se destacou como a cultura agrícola com maior extensão de área cultivada e principal responsável pela expansão da fronteira agrícola. Entretanto, para alcançar elevadas produtividades é importante considerar dois aspectos para o bom desenvolvimento vegetal: a existência de água disponível no solo e a distribuição radicular da planta ao longo do perfil do solo (Taiz \& Zeiger, 2004).

No entanto, deve-se considerar que a quantidade de água disponível no solo é tanto maior quanto mais profunda a camada considerada. Assim, uma forma de aumentar a disponibilidade de água para as plantas é procurar conduzir o sistema radicular para essas camadas. Para um bom desenvolvimento e aprofundamento das raízes, é preciso que o solo não tenha impedimentos físicos e, ou, químicos que dificultem o crescimento (Mengel \& Kyrkby, 2001).

A adubação com B tem efeito positivo no crescimento radicular como constatado por Shelp (1993). O B está relacionado a muitos processos fisiológicos da planta que são influenciados pela sua deficiência, como transporte de açúcares, síntese da parede celular, lignificação, estrutura da parede celular, metabolismo de carboidratos, metabolismo de RNA, respiração, metabolismo de AIA, metabolismo fenólico, metabolismo de ascorbato e integridade da membrana plasmática. Entre as diversas funções, duas estão muito bem definidas, síntese de parede celular e integridade da membrana plasmática (Cakmak \& Römheld, 1998). O crescimento radicular é resultante dos processos de divisão e expansão celular. De acordo com Shelp (1993), o B é necessário em ambos os processos, e a ocorrência de deficiência inibe o desenvolvimento radicular.

A escolha da melhor fonte de nutriente para aplicação no solo depende do tipo de solo, da cultura e do regime hídrico. A maioria dos adubos boratados apresenta alta solubilidade, assim o B está sujeito à grande mobilidade no solo e, consequentemente, ao maior grau de lixiviação no perfil do solo, principalmente no arenoso. Dessa forma, a preferência é por fontes de solubilidade lenta, portanto, menos suscetíveis a perdas por lixiviação (Mortvedt, 1994). $\mathrm{O}$ ácido bórico $\left(\mathrm{H}_{3} \mathrm{BO}_{3}\right)$ encontra-se na forma de cristais de ácido bórico com teor de B na faixa de 17 $18 \%$. Em razão da sua alta solubilidade em água e baixa reatividade com o solo, essa fonte é extremamente suscetível à lixiviação (Byers et al., 2001)

A colemanita caracteriza-se por ser um borato de cálcio $\left(\mathrm{Ca}_{2} \mathrm{~B}_{6} \mathrm{O}_{11}\right)$ de ocorrência na natureza muitas vezes associada à ulexita, podendo até mesmo ser resultante de sua alteração. Seu teor de B é variável de $10-16 \%$ e apresenta moderada solubilidade. Essa fonte é normalmente usada com maior frequência em solos arenosos, pois é considerada fonte de B menos solúvel e, portanto, menos sujeita à lixiviação nesse tipo de solo (Murphy \& Walsh, 1972).

A ocorrência de períodos de seca causa impactos diferenciados na produtividade da soja, evidenciando cada vez mais a necessidade de um sistema radicular mais profundo na tentativa de diminuir os riscos da produção agrícola. Portanto, a adubação com B pode ter como resultado sistemas radiculares mais desenvolvidos e mais eficientes em buscar água e nutrientes em profundidade no solo (Mortvedt, 1994; Mengel \& Kirkby, 2001). 
Este trabalho teve como objetivo avaliar o efeito de doses e fontes de B aplicado em solo de textura média, submetido a três tensões de água, e suas interações no crescimento e na absorção de B pela cultura da soja.

\section{MATERIAL E MÉTODOS}

O experimento foi conduzido em casa de vegetação, no Núcleo de Estações Experimentais da Universidade Estadual do Oeste do Paraná - UNIOESTE, Campus de Marechal Cândido Rondon, PR, sob as coordenadas geográficas $54^{\circ} 22^{\prime} \mathrm{W}$ longitude, latitude $24^{\circ} 46^{\prime} \mathrm{S}$ e altitude média de $420 \mathrm{~m}$.

O delineamento experimental utilizado foi em parcelas subdivididas, em esquema fatorial $(5 \times 2 \times 3)$ com quatro repetições. A subdivisão das parcelas foi conforme as tensões de água no solo.

Os fatores estudados foram constituídos por cinco doses de $\mathrm{B}\left(0 ; 0,25 ; 0,5 ; 1,0 ; \mathrm{e} 2,0 \mathrm{mg} \mathrm{dm}^{-3}\right)$ aplicadas com duas fontes, uma mais solúvel, o ácido bórico com $17 \%$ de B, e outra menos solúvel, Colemanita com $8 \%$ de $\mathrm{B}$.

O outro fator foi constituído pelos três níveis de tensão de água no solo (potencial de água no solo), que foram definidos pela curva de retenção de água no solo, utilizando o método da câmara de pressão de Richards - "panelas de pressão", em que a tensão 1 se aproxima a $100 \%$ da capacidade de campo $(0,01 \mathrm{MPa})$; a tensão 2 , a $80 \%$ da capacidade de campo $(0,03 \mathrm{MPa})$; e a tensão 3 , a $65 \%$ da capacidade de campo $(0,1 \mathrm{MPa})$.

A semeadura foi realizada no dia 18/03/2008, utilizando-se o cultivar de soja CD 219 de ciclo precoce e hábito de crescimento determinado.

Realizou-se o tratamento das sementes com Fipronil $\left(250 \mathrm{~g} \mathrm{~L}^{-1}\right)$ na dose de $150 \mathrm{~mL}^{-100 \mathrm{~kg}^{-1} \mathrm{de}}$ semente, mais Carbendazim $\left(150 \mathrm{~g} \mathrm{~L}^{-1}\right)+$ Thiram $\left(350 \mathrm{~g} \mathrm{~L}^{-1}\right)$, na dose de $200 \mathrm{~mL} 100 \mathrm{~kg}^{-1}$ de semente. Foram semeadas cinco sementes por vaso. Nove dias após a emergência das plantas, realizou-se desbaste deixando duas plantas por vaso. O experimento foi implantado e conduzido em vaso, os quais possuíam capacidade para $5 \mathrm{dm}^{3}$ de solo. Utilizou-se amostra do horizonte A de um Latossolo Vermelho eutroférrico de textura média, cujas características químicas e físicas são apresentadas no quadro 1, coletado na região do arenito Caiuá, previamente corrigido para pH 6,0 e fertilizado com P, K e micronutrientes. Como fonte de $\mathrm{P}$, foi utilizado superfosfato triplo (45\% de $\mathrm{P}_{2} \mathrm{O}_{5}$ ), fornecendo $300 \mathrm{mg} \mathrm{dm}^{-3}$; e como fonte de $\mathrm{K}$, adicionou-se cloreto de potássio $\mathrm{KCl}\left(60 \%\right.$ de $\left.\mathrm{K}_{2} \mathrm{O}\right)$, fornecendo $150 \mathrm{mg} \mathrm{dm}^{-3}$. Essas fontes foram adicionadas ao solo após a correção do $\mathrm{pH}$, o qual foi realizado pelo método da curva de incubação com $\mathrm{CaCO}_{3}$ para elevar o $\mathrm{pH}$ do solo a 6,0 , utilizando $769 \mathrm{~kg} \mathrm{ha}^{-1}$ de $\mathrm{CaCO}_{3}$ e $161,8 \mathrm{~kg} \mathrm{ha}^{-1}$ de $\mathrm{MgCO}_{3}$, respeitando a relação 4:1. A fertilização nitrogenada ocorreu em duas etapas: a primeira, 12 dias após semeadura, e a segunda, 30 dias após, fornecendo um total de $100 \mathrm{mg} \mathrm{dm}^{-3}$ de $\mathrm{N}$ adicionado como ureia. A adubação básica com micronutrientes consistiu-se na aplicação de 3,66 mg Mn; 1,33 mg Cu; 1,55 mg Fe; $0,15 \mathrm{mg}$ Mo e $4 \mathrm{mg}$ de $\mathrm{Zn}$ por $\mathrm{dm}^{3}$ de solo fornecidos na forma de $\mathrm{MnCl}_{2} \cdot 4 \mathrm{H}_{2} \mathrm{O}, \mathrm{CuSO}_{4} \cdot 5 \mathrm{H}_{2} \mathrm{O}, \mathrm{FeSO}_{4} \cdot 7 \mathrm{H}_{2} \mathrm{O}$, $\mathrm{NaMoO}_{4} \cdot 2 \mathrm{H}_{2} \mathrm{O}$ e $\mathrm{ZnSO}_{4} \cdot 7 \mathrm{H}_{2} \mathrm{O}$ (Novais et al., 1991). Essa adubação ocorreu 10 dias após a semeadura da cultura, diretamente em cada vaso, fornecida via solução. A aplicação dos tratamentos (fontes e doses de B) também ocorreu 10 dias após a semeadura, via solução, com auxílio de uma seringa graduada, que possuía uma agulha de $10 \mathrm{~cm}$ de comprimento, inserida no solo em toda a circunferência do vaso.

O controle da umidade do solo foi efetuado por um sistema autoirrigante subsuperficial, o qual permitia a reposição automática de água conforme a evapotranspiração do vaso. Esse sistema operava com uma cápsula de cerâmica porosa (vela de filtro da marca Stefani com dimensões de 10,5 cm de altura e $5,5 \mathrm{~cm}$ de diâmetro).

O solo foi depositado dentro do vaso em cima da cápsula porosa. Um microtubo flexível transparente,

Quadro 1. Características químicas e granulométricas do horizonte A do Latossolo Vermelho eutroférrico coletado para a instalação do experimento

\begin{tabular}{lr}
\hline \multicolumn{1}{c}{ Atributo } & Valor \\
\hline $\mathrm{pH}\left(\mathrm{CaCl}_{2}\right)$ & 4,70 \\
$\mathrm{P}\left(\mathrm{mg} \mathrm{dm}^{-3}\right)^{(1)}$ & 2,06 \\
$\mathrm{~K}\left(\mathrm{cmol}_{\mathrm{c}} \mathrm{dm}^{-3}\right)^{(1)}$ & 1,15 \\
$\mathrm{Ca}\left(\mathrm{cmol}_{\mathrm{c}} \mathrm{dm}^{-3}\right)^{(2)}$ & 0,25 \\
$\mathrm{Mg}\left(\mathrm{cmol}_{\mathrm{c}} \mathrm{dm}^{-3}\right)^{(2)}$ & 0,07 \\
$\mathrm{Al}\left(\mathrm{cmol}_{\mathrm{c}} \mathrm{dm}^{-3}\right)^{(2)}$ & 0,15 \\
$\mathrm{H}+\mathrm{Al}\left(\mathrm{cmol}_{\mathrm{c}} \mathrm{dm}^{-3}\right)^{(3)}$ & 3,05 \\
$\mathrm{SB}\left(\mathrm{cmol}_{\mathrm{c}} \mathrm{dm}^{-3}\right)$ & 1,47 \\
$\mathrm{CTC}\left(\mathrm{cmol}_{\mathrm{c}} \mathrm{dm}^{-3}\right)$ & 4,52 \\
$\mathrm{Matéria} \mathrm{orgânica}\left(\mathrm{g} \mathrm{dm}^{-3}\right)^{(4)}$ & 3,42 \\
$\mathrm{~V}(\%)$ & 32,50 \\
$\mathrm{~m}(\%)$ & 9,60 \\
$\mathrm{Fe}\left(\mathrm{mg} \mathrm{dm}^{-3}\right)^{(1)}$ & 23,20 \\
$\mathrm{Mn}\left(\mathrm{mg} \mathrm{dm}^{-3}\right)^{(1)}$ & 36,00 \\
$\mathrm{Cu}\left(\mathrm{mg} \mathrm{dm}^{-3}\right)^{(1)}$ & 3,30 \\
Zn $\left(\mathrm{mg} \mathrm{dm}^{-3}\right)^{(1)}$ & 1,00 \\
$\mathrm{~B}\left(\mathrm{mg} \mathrm{dm}^{-3}\right)^{(5)}$ & 0,30 \\
Areia $\left(\mathrm{g} \mathrm{kg}^{-1}\right)$ & 685,60 \\
Silte $\left(\mathrm{g} \mathrm{kg}^{-1}\right)$ & 48,00 \\
Argila $\left(\mathrm{g} \mathrm{kg}^{-1}\right)$ & 266,40 \\
\hline
\end{tabular}

(1) Extrator Mehlich-1; ${ }^{(2)}$ Extrator KCl $1 \mathrm{~mol} \mathrm{~L}^{-1}$; ${ }^{(3)} \mathrm{pH}$ SMP $(7,5)$; ${ }^{(4)}$ Método Walkey-Black; e ${ }^{(5)}$ Água quente. Caracterizações químicas e físicas realizadas, respectivamente, pelos laboratórios de Química Ambiental e Instrumental da e de Física do Solo e Nutrição Mineral de Plantas da UNIOESTE - Campus de Marechal Cândido Rondon (PR). 
nas dimensões $1 / 8$ " x $1,5 \mathrm{~mm}$ e com comprimento variável, conforme nível de tensão de água no solo exigido pelo tratamento, conectava a cápsula de cerâmica ao reservatório de nível constante (garrafa 'pet' com capacidade para $2 \mathrm{~L}$ ), suspensa com arame galvanizado abaixo do vaso. As garrafas 'pet' receberam uma cobertura de tinta de cor preta e uma segunda camada de proteção em papel-alumínio.

Dezesseis dias após semeadura, todos os tratamentos estiveram sob o mesmo potencial de água no solo, - $0,01 \mathrm{MPa}$ (100 \% da capacidade de campo $\mathrm{CC}$ ), correspondente à umidade gravimétrica do solo de aproximadamente $16 \%$. Os outros dois potenciais de água no solo foram estabelecidos 17 dias após a semeadura pela alteração da altura da coluna de água, que foi estabelecida pela distância entre o vaso e o reservatório, que variou conforme os tratamentos. No tratamento com $-0,01 \mathrm{MPa}(100 \%$ da CC), se manteve a mesma altura correspondente a $35 \mathrm{~cm}$; para os demais tratamentos, a altura foi ajustada para $50 \mathrm{~cm}$ $(-0,03 \mathrm{MPa}$ ou $80 \%$ da CC) e para $60 \mathrm{~cm}(-0,1 \mathrm{MPa}$ ou $65 \%$ da CC).

Esse sistema de irrigação é um aprimoramento do modelo proposto por Montanheiro et al. (1979), o qual foi utilizado por Bataglia (1989) em experimento envolvendo fertilidade do solo e adaptado por BonfimSilva et al. (2007).

Nos últimos três dias de condução do experimento, para simular uma condição de déficit hídrico, suspendeu-se o fornecimento de água do tratamento (-0,1 $\mathrm{MPa}$ ou $65 \%$ da CC) para diminuir a disponibilidade de água para as plantas.

Avaliou-se o teor relativo de água nas folhas durante os últimos três dias de condução do experimento, de acordo com o método proposto por Barrs (1968). Determinou-se a umidade gravimétrica do solo, em seis períodos - 01/04, 17/04, 27/04, 29/04, 30/04 e 01/05, retirando-se duas amostras de cada vaso com um tubo de PVC de 1/2" de todo o perfil do vaso. As amostras de solo foram acondicionadas em latas de alumínio e levadas ao laboratório para pesagem. Em seguida, as latas foram colocadas em estufa de circulação forçada de ar à temperatura de $105^{\circ} \mathrm{C}$ até atingirem massa constante.

O experimento foi conduzido até o início do florescimento do cultivar de soja com 43 dias após semeadura. Após esse período, foram avaliadas as seguintes variáveis: volume radicular e massa de matéria seca de folhas, caule e raiz. O volume radicular foi medido pelo deslocamento de água em uma proveta, após a imersão do sistema radicular.

Para a determinação da massa de matéria seca dos diferentes órgãos, as plantas foram seccionadas e colocadas em sacos de papel, etiquetadas e levadas à estufa de circulação forçada de ar a $65{ }^{\circ} \mathrm{C}$ até atingirem massa constante. Em seguida, determinouse a massa de matéria seca utilizando balança de precisão.
Para definir o teor de B no solo, utilizou-se o método proposto por Abreu et al. (1994), o qual usou uma solução de cloreto de bário $1,25 \mathrm{~g} \mathrm{~L}^{-1}$ com aquecimento assistido em micro-ondas. Esse método ainda utiliza o reagente colorimétrico mais utilizado para a determinação de B em solo a Azometina-H.

Para análise do teor de B no tecido foliar, foram coletadas as primeiras folhas maduras localizadas abaixo do ponto de crescimento da planta (Srivastava \& Gupta, 1996). As amostras foram incineradas em mufla à temperatura de $550{ }^{\circ} \mathrm{C}$ durante $3 \mathrm{~h}$ até obtenção de cinzas, que foram solubilizadas em $10 \mathrm{~mL}$ HCl 0,1 mol L$^{-1}$ (Wikner, 1986; Bataglia, 1991). Para discriminar o teor de $\mathrm{B}$, foi utilizado o método da Azometina-He a leitura em espectroscopia UV-VIS com comprimento de onda de $420 \mathrm{~nm}$ (Malavolta et al., 1997).

Os dados obtidos foram submetidos às análises de variância e regressão. Quando se detectaram diferenças significativas, as médias dos níveis de tensão de água no solo e das fontes de B aplicadas foram comparadas pelo teste de Tukey a $5 \%$. Para as médias das doses de B, foram escolhidos os modelos de regressão que melhor se ajustaram aos dados, com base na significância pelo teste $\mathrm{F}$, considerando os níveis de $5 \mathrm{e}$ $1 \%$ e o maior valor do coeficiente de determinação $\left(\mathrm{R}^{2}\right)$. Utilizou-se o programa estatístico SAEG versão 8.0 (UFV, 1999) para o processamento dos dados.

\section{RESULTADOS E DISCUSSÃO}

Os dados referentes à umidade gravimétrica do solo durante a condução do experimento, em razão dos diferentes níveis de tensão de água no solo, são apresentados na figura 1. A umidade gravimétrica do solo sob o nível de tensão de água no solo de $0,01 \mathrm{MPa}$ (100\% da CC) permaneceu constante durante todo o experimento de 0,106 a $0,109 \mathrm{~kg} \mathrm{~kg}^{-1}$ (Figura 1 ).

Quando a tensão de água no solo foi mantida em $0,1 \mathrm{MPa}$ (65\% da CC), a umidade gravimétrica manteve-se com valores médios variando de 0,106 a $0,109 \mathrm{~kg} \mathrm{~kg}^{-1}$, durante o transcorrer do experimento. Entretanto, nos três últimos dias de condução do experimento (29 e 30/4 e 01/05) houve redução significativa no teor de água do solo passando para valores na ordem de 0,079; 0,073; e 0,062 kg kg-1 de umidade, respectivamente. Esses resultados podem ser explicados em virtude de que foi cortado o fornecimento de água nesse tratamento.

No quadro 2, são apresentados os dados referentes à umidade gravimétrica do solo, obtidos ao final do experimento em razão dos níveis de tensão de água no solo e das fontes e doses de B aplicadas. Houve diferença significativa $(p<0,05)$ apenas para os níveis de tensão de água no solo. Os resultados já eram esperados, visto que foram mantidos diferentes teores de umidade no solo. A umidade gravimétrica ao final do experimento variou de 0,$161 ; 0,139 ;$ e $0,77 \mathrm{~kg} \mathrm{~kg}^{-1}$ 
de umidade com os níveis de tensão de 0,01;0,03; e $0,1 \mathrm{MPa}$, respectivamente (Quadro 2).

No quadro 2, são evidenciados os valores médios da umidade gravimétrica nos diferentes níveis de tensão de água no solo, obtidos no último dia de avaliação, que, comparando com o teor de umidade do solo na CC, ou seja, em torno de $0,165 \mathrm{~kg} \mathrm{~kg}^{-1}$ (Figura 1), observou-se que a umidade volumétrica do solo encontrava-se com $98 \%$ da CC na tensão $1(0,01 \mathrm{MPa})$; $84 \%$, na tensão $2(0,03 \mathrm{MPa})$; e $47 \%$, na tensão $3(0,1$ $\mathrm{MPa})$. Entretanto, ressalta-se, que esse menor teor de umidade obtido na tensão 3 foi apenas nos últimos três dias de experimento, em decorrência do corte de fornecimento de água nesse tratamento, conforme mencionado anteriormente.

Os dados referentes ao teor relativo de água nas folhas de soja nos três últimos dias de avaliação, em razão dos níveis de tensão de água no solo e das fontes e doses de B, são apresentados no quadro 3. Os resultados evidenciaram efeitos significativos $(\mathrm{p}<0,05)$ para os níveis de tensão de água do solo e interação significativa entre os níveis de tensão de água no solo e nas doses de $\mathrm{B}$ aplicadas para o teor relativo de água nas folhas de soja, na avaliação realizada no primeiro dia.

Quando os níveis de umidade do solo foram mantidos na CC $(-0,01 \mathrm{MPa})$ e a $80 \%$ da CC $(-0,03 \mathrm{MPa})$, o teor relativo de água nas folhas de soja não foi influenciado significativamente em nenhuma das avaliações, de modo que os valores médios variaram de 94,0 e 92,2 $\%$ no primeiro dia de avaliação; de 94,3 e $92,5 \%$, no segundo dia; e de 88,5 e $91,6 \%$, no terceiro dia (Quadro 3). Resultados semelhantes foram reportados por Fioreze et al., (2011). O autor, avaliando o efeito do déficit hídrico em três cultivares de soja, verificou que o teor relativo de água nas folhas nos tratamentos sob manejo normal de irrigação (100 $\%$ da CC) se manteve superior a $90 \%$, durante todo o período de avaliação.

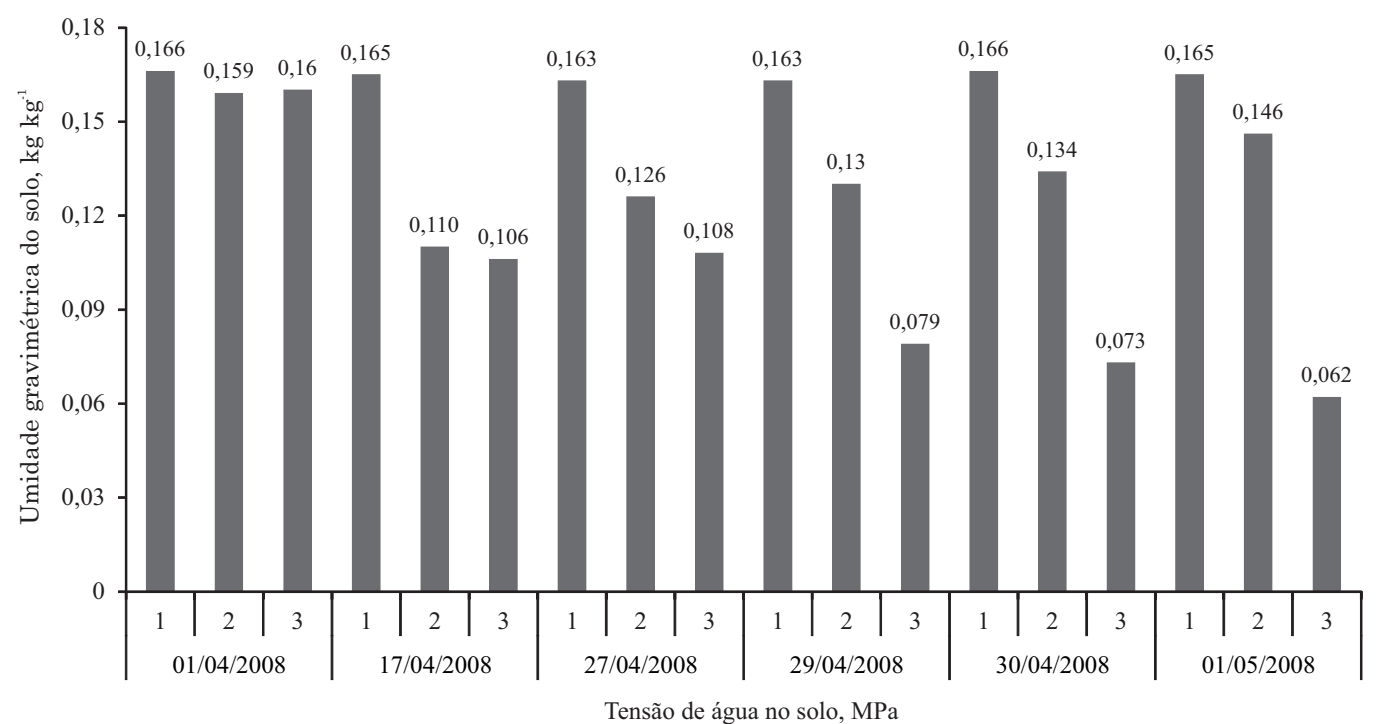

Figura 1. Umidade gravimétrica do solo durante a condução do experimento em função dos níveis de tensão de água no solo (1 = 0,01 MPa; 2 = 0,03 MPa; e 3 = 0,1 MPa).

Quadro 2. Umidade gravimétrica do solo no final do experimento em razão dos níveis de tensão de água no solo e das fontes e doses de B aplicadas

\begin{tabular}{|c|c|c|c|c|c|c|c|c|c|}
\hline \multirow{3}{*}{$\begin{array}{l}\text { Dose } \\
\text { de B }\end{array}$} & \multicolumn{9}{|c|}{ Tensão (MPa) } \\
\hline & \multicolumn{3}{|c|}{0,01} & \multicolumn{3}{|c|}{0,03} & \multicolumn{3}{|c|}{0,1} \\
\hline & Ac. bórico & Colemanita & Média & Ac. bórico & Colemanita & Média & Ac. bórico & Colemanita & Média \\
\hline $\mathrm{mg} \mathrm{dm}{ }^{-3}$ & & & & & $\mathrm{~kg} \mathrm{~kg}^{-1}$ & & & & \\
\hline 0,00 & 0,158 & 0,136 & 0,147 & 0,125 & 0,155 & 0,140 & 0,113 & 0,086 & 0,099 \\
\hline 0,25 & 0,177 & 0,147 & 0,162 & 0,131 & 0,150 & 0,141 & 0,066 & 0,066 & 0,066 \\
\hline 0,50 & 0,169 & 0,172 & 0,170 & 0,135 & 0,145 & 0,140 & 0,079 & 0,061 & 0,070 \\
\hline 1,00 & 0,163 & 0,151 & 0,157 & 0,151 & 0,147 & 0,149 & 0,085 & 0,065 & 0,075 \\
\hline 2,00 & 0,171 & 0,169 & 0,170 & 0,121 & 0,127 & 0,124 & 0,079 & 0,070 & 0,075 \\
\hline Média & & $0,161 \mathrm{~A}$ & & & $0,139 \mathrm{~B}$ & & & $0,077 \mathrm{C}$ & \\
\hline CV (\%) & & & & & 22,98 & & & & \\
\hline
\end{tabular}

Médias seguidas de letras diferentes na comparação das tensões de água do solo diferem entre si pelo teste de Tukey a 5 \%. 
Quadro 3. Teor relativo de água nas folhas de soja nos três últimos dias de avaliação em razão dos níveis de tensão de água no solo e das fontes e doses de B aplicadas

\begin{tabular}{|c|c|c|c|c|c|c|c|c|c|}
\hline \multirow{3}{*}{$\begin{array}{l}\text { Dose } \\
\text { de B }\end{array}$} & \multicolumn{9}{|c|}{ Tensão (MPa) } \\
\hline & \multicolumn{3}{|c|}{0,01} & \multicolumn{3}{|c|}{0,03} & \multicolumn{3}{|c|}{0,1} \\
\hline & Ac. bórico & Colemanita & Média & Ac. bórico & Colemanita & Média & Ac. bórico & Colemanita & Média \\
\hline \multicolumn{10}{|l|}{$\mathrm{mg} \mathrm{dm} \mathrm{m}^{-3}$} \\
\hline \multicolumn{10}{|c|}{ Teor relativo de água nas folhas $(\%)-1^{\circ}$ dia } \\
\hline 0,00 & 93,14 & 96,14 & $94,64 \mathrm{Aa}$ & 93,47 & 90,21 & $91,84 \mathrm{Aa}$ & 88,58 & 81,44 & $85,01 \mathrm{Bb}$ \\
\hline 0,25 & 93,84 & 93,67 & $93.75 \mathrm{Aa}$ & 92,63 & 93,04 & $92,83 \mathrm{Aa}$ & 88,84 & 84,76 & $86,80 \mathrm{Bb}$ \\
\hline 0,50 & 96,22 & 93,71 & $94.96 \mathrm{Aa}$ & 92,99 & 91,85 & $92,42 \mathrm{Aa}$ & 86,33 & 83,68 & $85,00 \mathrm{Bb}$ \\
\hline 1,00 & 92,55 & 93,49 & $93.00 \mathrm{Aa}$ & 92,51 & 93,77 & $93,14 \mathrm{Aa}$ & 90,65 & 85,00 & $87,82 \mathrm{Aab}$ \\
\hline 2,00 & 96,18 & 90,74 & 93,46 Aa & 92,24 & 89,10 & $90,67 \mathrm{Aa}$ & 90,13 & 97,39 & $93,76 \mathrm{Aab}$ \\
\hline Média & & $93,97 \mathrm{~A}$ & & & $92,18 \mathrm{~A}$ & & & $87,68 \mathrm{~B}$ & \\
\hline CV (\%) & & & & & 5,12 & & & & \\
\hline \multicolumn{10}{|c|}{ Teor relativo de água nas folhas (\%) $-2^{\circ}$ dia } \\
\hline 0,00 & 95,37 & 92,92 & $94,14^{\mathrm{NS}}$ & 89,86 & 94,05 & $91,96^{\mathrm{NS}}$ & 86,24 & 75,02 & $80,63^{\mathrm{NS}}$ \\
\hline 0,25 & 92,56 & 90,27 & 91,42 & 93,81 & 92,84 & 93,32 & 84,41 & 91,62 & 88,02 \\
\hline 0,50 & 94,06 & 92,48 & 93,27 & 90,67 & 91,89 & 91,28 & 80,46 & 81,35 & 80,90 \\
\hline 1,00 & 93,80 & 92,72 & 93,26 & 93,27 & 92,52 & 92,89 & 84,59 & 80,48 & 82,54 \\
\hline 2,00 & 93,59 & 95,09 & 94,34 & 93,88 & 92,32 & 93,10 & 83,49 & 90,56 & 87,02 \\
\hline Média & & $94,29 \mathrm{~A}$ & & & $92,51 \mathrm{~A}$ & & & $83,82 \mathrm{~B}$ & \\
\hline CV (\%) & & & & & 7,57 & & & & \\
\hline \multicolumn{10}{|c|}{ Teor relativo de água nas folhas $(\%)-3^{\circ}$ dia } \\
\hline 0,00 & 87,84 & 85,43 & $86,63^{\mathrm{NS}}$ & 89,26 & 90,15 & $89,70^{\mathrm{NS}}$ & 56,83 & 51,59 & $54,21^{\mathrm{NS}}$ \\
\hline 0,25 & 90,10 & 87,22 & 88,66 & 91,65 & 93,27 & 92,46 & 54,52 & 68,19 & 61,35 \\
\hline 0,50 & 92,05 & 91,03 & 91,54 & 89,86 & 92,35 & 91,10 & 62,77 & 54,59 & 58,68 \\
\hline 1,00 & 89,58 & 87,14 & 88,36 & 93,70 & 94,42 & 94,06 & 72,83 & 86,73 & 79,78 \\
\hline 2,00 & 86,46 & 87,91 & 87,18 & 94,00 & 86,82 & 90,41 & 58,74 & 64,78 & 61,76 \\
\hline Média & & $88,48 \mathrm{~A}$ & & & $91,55 \mathrm{~A}$ & & & $63,15 \mathrm{~B}$ & \\
\hline CV (\%) & & & & & 16,21 & & & & \\
\hline
\end{tabular}

NS não significativo. Médias seguidas da mesma letra, maiúscula na linha e minúscula na coluna, não diferem entre si pelo teste de Tukey a $5 \%$.

Neste trabalho, quando se manteve a umidade do solo em $65 \%$ da CC (-0,1 MPa), o teor relativo de água nas folhas de soja apresentou-se estatisticamente inferior em todas as avaliações (Quadro 3). Esses resultados podem ser explicados por causa da menor disponibilidade de água presente no solo, conforme apresentado na figura 1 e no quadro 2. Esse menor teor de água na folha foi em decorrência do processo de perda de água pela transpiração das plantas; e como a disponibilidade de água no solo era baixa, a planta tinha dificuldade de absorver água para repor as perdas da transpiração.

$\mathrm{Na}$ figura 2, são apresentados os resultados referentes ao ajuste obtido entre o teor relativo de água nas folhas e a umidade gravimétrica do solo, no último dia de avaliação (01/05/2008). Obteve-se um ajuste polinomial quadrático com coeficiente de determinação $\left(\mathrm{R}^{2}\right)$ de $0,62(\mathrm{p}<0,01)$, sendo obtido o máximo teor relativo de água nas folhas de $92,0 \%$, quando o solo apresentou $0,159 \mathrm{~kg} \mathrm{~kg}^{-1}$ de umidade gravimétrica.
A interação significativa entre os níveis de tensão de água no solo e as doses de B aplicadas para o teor relativo de água nas folhas de soja, no primeiro dia de avaliação, é apresentada na figura $2 \mathrm{~b}$. Quando a umidade foi mantida na CC $(-0,01 \mathrm{MPa})$ ou com $80 \%$ de umidade $(-0,03 \mathrm{MPa})$, o teor relativo de água nas folhas de soja não foi influenciado pelas doses de B aplicadas, apresentando valores médios na ordem de 93,9 e $92,2 \%$.

Entretanto, quando se manteve a umidade em $65 \%$ da CC (-0,1 MPa), as doses de B proporcionaram incrementos lineares positivos no teor relativo de água nas folhas de soja, de modo que houve redução de perda de água de $4,3 \%$ para cada $\mathrm{mg} \mathrm{dm}^{-3}$ de B aplicado ao solo (Figura 2b). Esses resultados demonstraram que a aplicação de B proporcionou menores perdas de água pelas folhas de soja. Esse fato pode ser atribuído à função do B, relacionada à síntese de parede celular e à integridade da membrana plasmática, conforme apresentado por Cakmak \& Römheld (1998). 

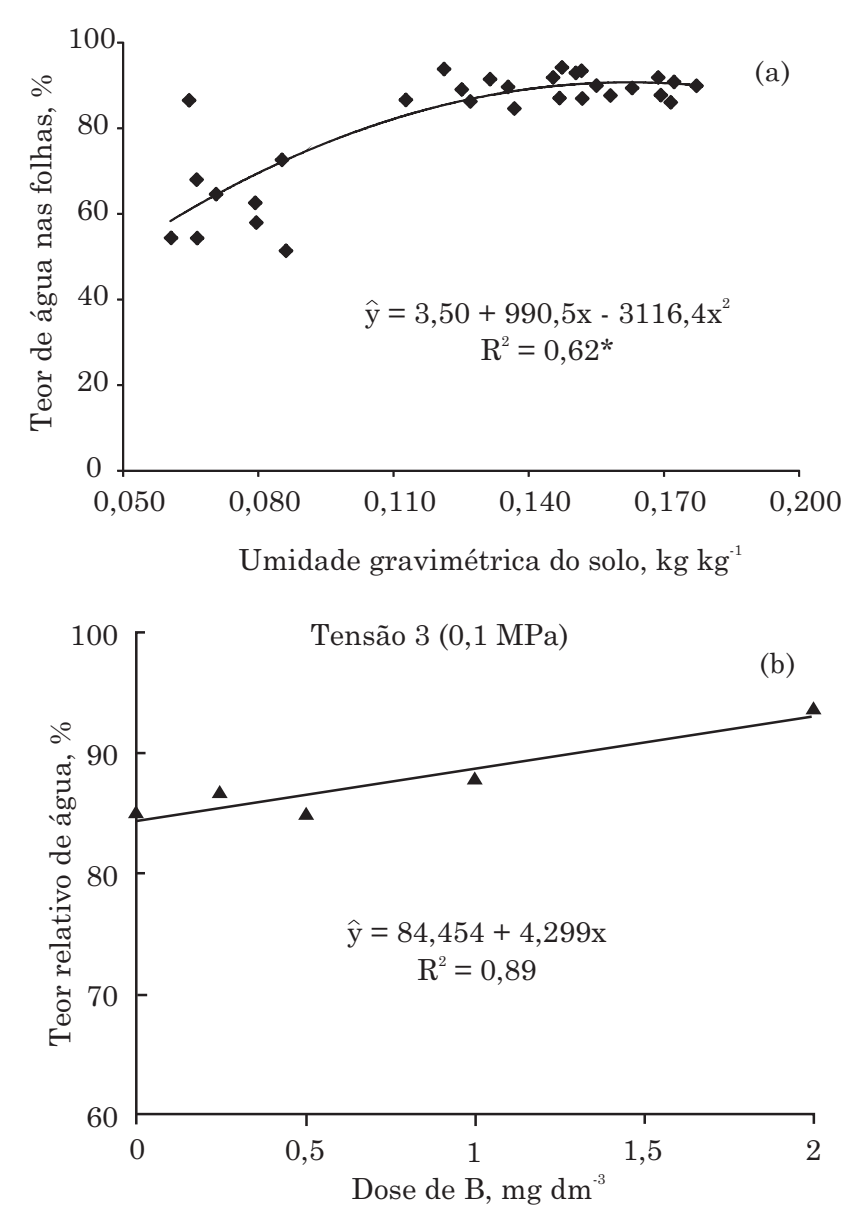

Figura 2. Ajuste obtido entre os valores de teor relativo de água nas folhas e a umidade gravimétrica do Latossolo Vermelho eutroférrico de textura arenosa, no último dia de avaliação (a); e teor relativo de água nas folhas de soja no primeiro dia avaliação em função da tensão de água no solo e das doses de B aplicadas (b).

A produção de matéria seca de folhas, caule e total de plantas de soja não foi influenciada pelos níveis de tensão de água no solo e pelas fontes e doses de B (Quadro 4). Apesar de os níveis de tensão de água no solo não influenciar significativamente, observou-se que houve redução da produção de matéria seca de folha de soja em torno de $12 \%$, comparando-se os valores obtidos sob CC (0,01 MPa) e a $65 \%$ de umidade (0,1 MPa) (Quadro 4). Para a produção de matéria seca de caule e total, essa redução foi na ordem de 3,48 e 8,21\%, respectivamente. Mattos et al. (2005) verificaram que a produção de matéria seca de lâminas foliares de Brachiaria spp. diminuiu linearmente com o potencial hídrico do solo. $\mathrm{O}$ autores verificaram que houve decréscimo de $26 \%$, comparando-se os valores obtidos sob CC (-0,01 MPa) e sob ponto de murcha permanente $(-1,5 \mathrm{MPa})$.

Essa falta de resposta às doses de $\mathrm{B}$ aplicadas, alcançadas neste estudo para a produção de matéria seca dos diferentes órgãos da parte aérea, pode ser justificada pelo alto nível desse elemento presente no solo $\left(0,32 \mathrm{mg} \mathrm{dm}^{-3}\right)$. Em seu trabalho, Buzetti et al. (1990) observaram níveis críticos no solo entre 0,11 e $0,23 \mathrm{mg} \mathrm{dm}^{-3}$ de B para a soja, usando duas doses de calcário em um Latossolo.

$\mathrm{Na}$ literatura brasileira, os dados referentes à aplicação de B em algumas culturas anuais têm-se apresentado contraditórios, principalmente pela grande variabilidade das condições físicas e químicas dos solos cultivados e pelas necessidades nutricionais das culturas. Observaram-se respostas à aplicação de B por vários pesquisadores para a cultura da soja (Buzetti et al., 1990; Galrão, 1990; Rerkasem et al., 1997; Ferreira et al., 2001; Ghanati et al., 2005).

Avaliando 10 classes de solo do Estado de Pernambuco, Lima et al. (2007) verificaram resposta às doses de $\mathrm{B}\left(0,2,4,6 \mathrm{e} 12 \mathrm{mg} \mathrm{dm}^{-3}\right)$, em apenas cinco dos 10 solos estudados, para a produção de matéria seca do milho. Rosolem et al. (2008) observaram a resposta da soja à adubação boratada, associada à calagem, em Latossolo Vermelho-Amarelo do Mato Grosso, e obtiveram resposta à aplicação de $\mathrm{B}\left(\right.$ até $1 \mathrm{~kg} \mathrm{ha}^{-1}$ ) apenas no terceiro ano do experimento. Os autores ainda evidenciaram que, nos três anos, mesmo no tratamento sem aplicação de B, os teores do nutriente nas folhas encontravam-se dentro da faixa considerada adequada para altas produtividades (Rosolem, 2007), ou seja, de 25 a $55 \mathrm{mg} \mathrm{kg}^{-1}$.

Entre os diferentes mecanismos de adaptação ao déficit hídrico que as plantas desenvolvem ocorre o aumento na densidade e profundidade de raízes (Taiz \& Zeiger, 2004). Os resultados podem ser evidenciados neste estudo. Observou-se que houve aumento de $49 \%$ na produção de matéria seca do sistema radicular da soja, quando se comparou os valores obtidos sob CC (-0,01 MPa) e com $65 \%$ de umidade do solo $(-0,1 \mathrm{MPa})$. Por sua vez, tal efeito não foi evidenciado para o volume radicular (Quadro 4).

Os resultados alcançados neste estudo evidenciaram que houve interação significativa entre fontes e doses de B aplicadas para as variáveis produção de matéria seca de raiz e volume radicular, e os dados desdobrados são apresentados na figura 3 . As doses de B aplicadas na forma de colemanita não influenciaram o desenvolvimento do sistema radicular, sendo obtidos valores médios de matéria seca de raiz de $2,94 \mathrm{~g} /$ vaso (Figura 3a). Para a aplicação de ácido bórico, a produção de matéria seca de raiz diminuiu linearmente com o aumento das doses de B, de modo que houve redução de $0,44 \mathrm{~g}$ de matéria seca de raiz para cada $\mathrm{mg} \mathrm{dm}^{-3}$ de B aplicada ao solo (Figura 3a).

Independentemente das fontes aplicadas, pode-se observar que, de modo geral, as doses de B interferiram negativamente o volume radicular (Figura $3 b$ ), sendo obtidos valores mínimos de volume radicular de 30,94 e $35,63 \mathrm{~cm}^{3} /$ vaso com a aplicação de 1,52 e 1,30 mg $\mathrm{dm}^{-3}$ de $\mathrm{B}$ para as fontes ácido bórico e colemanita, respectivamente. 
Quadro 4. Produção de matéria seca de folhas (MSF), de caule (MSC), total (MST), de raiz (MSR) e volume radicular de plantas de soja em razão dos níveis de tensão de água no solo e das fontes e doses de $\mathrm{B}$ aplicadas

\begin{tabular}{|c|c|c|c|c|c|c|}
\hline \multirow{3}{*}{ Dose de B } & \multicolumn{6}{|c|}{ Tensão (MPa) } \\
\hline & \multicolumn{2}{|c|}{0,01} & \multicolumn{2}{|c|}{0,03} & \multicolumn{2}{|c|}{0,1} \\
\hline & Ac. bórico & Colemanita & Ac. bórico & Colemanita & Ac. bórico & Colemanita \\
\hline \multicolumn{7}{|l|}{$\mathrm{mg} \mathrm{dm} \mathrm{m}^{-3}$} \\
\hline \multicolumn{7}{|c|}{ MSF, g/vaso } \\
\hline 0,00 & $9,44^{\mathrm{NS}}$ & $6,84^{\mathrm{NS}}$ & $6,96^{\mathrm{NS}}$ & $7,11^{\mathrm{NS}}$ & $7,57^{\mathrm{NS}}$ & $6,99^{\mathrm{NS}}$ \\
\hline 0,25 & 7,68 & 8,74 & 8,76 & 7,79 & 8,25 & 6,55 \\
\hline 0,50 & 5,67 & 7,21 & 9,69 & 7,14 & 6,18 & 6,58 \\
\hline 1,00 & 7,66 & 7,96 & 6,47 & 7,91 & 5,25 & 7,63 \\
\hline 2,00 & 5,32 & 8,78 & 7,16 & 7,89 & 5,08 & 5,91 \\
\hline Média & \multicolumn{2}{|c|}{$7,53 \mathrm{~A}$} & \multicolumn{2}{|c|}{$7,69 \mathrm{~A}$} & \multicolumn{2}{|c|}{$6,60 \mathrm{~A}$} \\
\hline CV (\%) & \multicolumn{6}{|c|}{37,09} \\
\hline \multicolumn{7}{|c|}{ MSC, g/vaso } \\
\hline 0,00 & $8,48^{\mathrm{NS}}$ & $6,07^{\mathrm{NS}}$ & $5,94^{\mathrm{NS}}$ & $6,01^{\mathrm{NS}}$ & $6,96^{\mathrm{NS}}$ & $7,03^{\mathrm{NS}}$ \\
\hline 0,25 & 6,47 & 7,73 & 7,67 & 6,97 & 8,45 & 5,93 \\
\hline 0,50 & 4,66 & 5,93 & 8,61 & 5,84 & 5,99 & 6,18 \\
\hline 1,00 & 6,34 & 7,21 & 5,85 & 6,80 & 4,62 & 7,86 \\
\hline 2,00 & 4,60 & 8,55 & 6,70 & 8,07 & 5,26 & 5,39 \\
\hline Média & \multicolumn{2}{|c|}{$6,60 \mathrm{~A}$} & \multicolumn{2}{|c|}{$6,85 \mathrm{~A}$} & \multicolumn{2}{|c|}{$6,37 \mathrm{~A}$} \\
\hline CV (\%) & \multicolumn{4}{|c|}{41,37} & & \\
\hline \multicolumn{7}{|c|}{ MST, g/vaso } \\
\hline 0,00 & $17,92^{\mathrm{NS}}$ & $12,91^{\mathrm{NS}}$ & $12,90^{\mathrm{NS}}$ & $13,12^{\mathrm{NS}}$ & $14,52^{\mathrm{NS}}$ & $14,02^{\mathrm{NS}}$ \\
\hline 0,25 & 14,15 & 16,47 & 16,43 & 14,76 & 16,71 & 12,48 \\
\hline 0,50 & 10,33 & 13,14 & 18,30 & 12,98 & 12,17 & 12,76 \\
\hline 1,00 & 13,99 & 15,17 & 12,32 & 14,71 & 9,86 & 15,50 \\
\hline 2,00 & 9,92 & 17,33 & 13,85 & 15,96 & 10,34 & 11,30 \\
\hline Média & \multicolumn{2}{|c|}{$14,13 \mathrm{~A}$} & \multicolumn{2}{|c|}{$14,53 \mathrm{~A}$} & \multicolumn{2}{|c|}{$12,97 \mathrm{~A}$} \\
\hline CV (\%) & \multicolumn{6}{|c|}{38,71} \\
\hline \multicolumn{7}{|c|}{ MSR, g/vaso } \\
\hline 0,00 & $3,18^{*}$ & $2,36^{\mathrm{NS}}$ & $2,20^{*}$ & $2,53^{\mathrm{NS}}$ & $2,95^{*}$ & $5,31^{\mathrm{NS}}$ \\
\hline 0,25 & 2,52 & 2,44 & 3,69 & 2,66 & 5,48 & 2,96 \\
\hline 0,50 & 1,59 & 2,11 & 3,92 & 2,44 & 3,83 & 3,17 \\
\hline 1,00 & 2,19 & 2,97 & 1,92 & 4,12 & 2,31 & 3,92 \\
\hline 2,00 & 1,67 & 2,52 & 2,50 & 3,60 & 2,67 & 2,35 \\
\hline Média & \multicolumn{2}{|c|}{$2,35 \mathrm{~B}$} & \multicolumn{2}{|c|}{$2,96 \mathrm{~B}$} & 3,5 & \\
\hline CV (\%) & & & & & & \\
\hline & & & ne radicular, & aso & & \\
\hline 0,00 & 49,25 * & 42,25 * & 38,75 * & 39,75 * & 42,75 * & 52,50 * \\
\hline 0,25 & 43,00 & 35,25 & 47,25 & 42,25 & 52,50 & 34,00 \\
\hline 0,50 & 25,00 & 34,75 & 58,75 & 38,50 & 41,25 & 35,00 \\
\hline 1,00 & 31,75 & 43,75 & 30,75 & 60,00 & 26,75 & 42,50 \\
\hline 2,00 & 27,50 & 35,50 & 42,00 & 45,75 & 30,00 & 29,75 \\
\hline Média & & $0 \mathrm{~A}$ & & & & $0 \mathrm{~A}$ \\
\hline CV (\%) & & & & & & \\
\hline
\end{tabular}

NS não significativo, * significativo a $5 \%$. Médias seguidas de letras iguais na comparação das tensões de água do solo não diferem entre si pelo teste de Tukey a $5 \%$. 

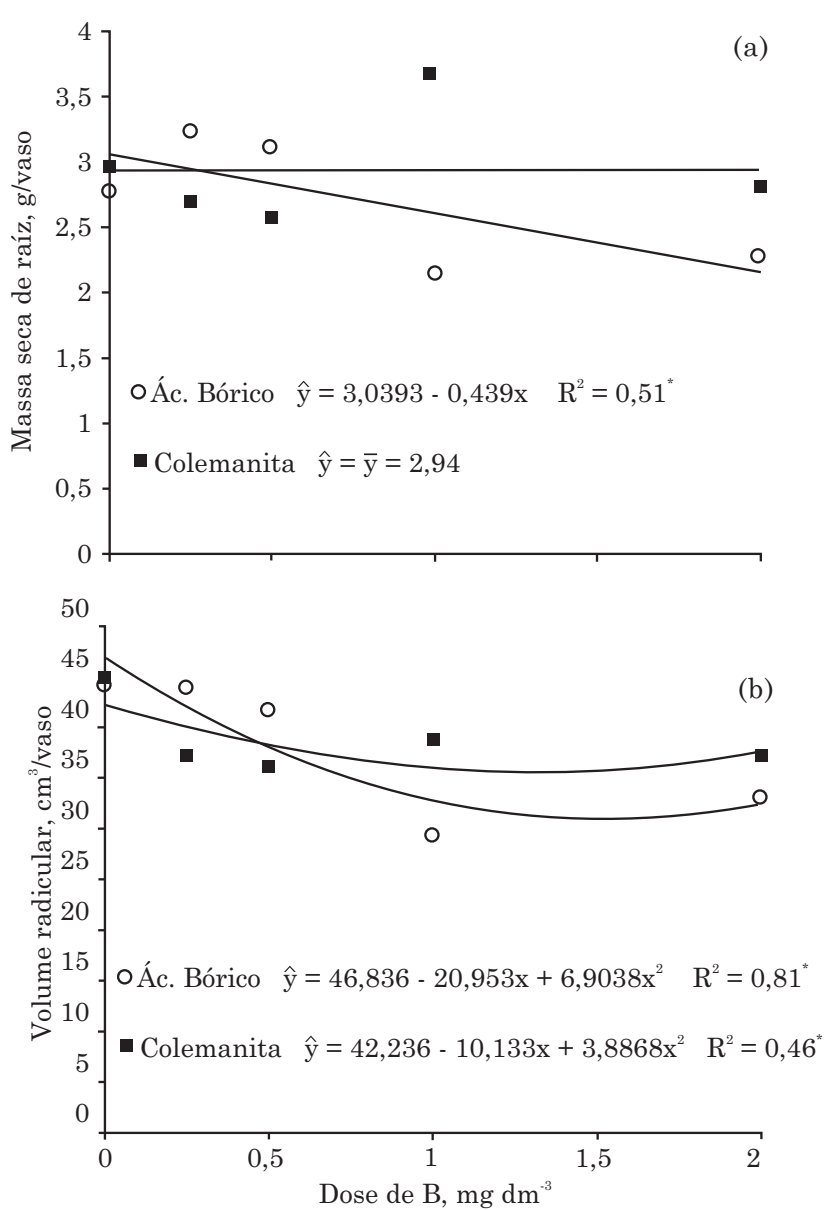

Figura 3. Produção de matéria seca de raiz (a) e volume radicular (b) de plantas de soja em função da interação significativa entre fontes e doses de B aplicadas ao solo.

Os teores de B no solo e no tecido foliar da soja em razão dos níveis de tensão de água no solo e das fontes e doses de B aplicadas são apresentados no quadro 5 . Houve apenas efeito significativo para tensão de água do solo e também para doses de B aplicadas, sem apresentar interação entre os fatores.

Os teores médios de B no solo extraídos com cloreto de bário variaram de 0,44 a 1,75 $\mathrm{mg} \mathrm{dm}^{-3}$ (Quadro 5). Independentemente da fonte de aplicação, as doses adicionadas de $\mathrm{B}$ aumentaram linearmente os teores do nutriente extraído pelo cloreto de bário (Figura 4a), sendo observado aumento na ordem de $0,44 \mathrm{mg} \mathrm{dm}^{-3}$ no teor de B no solo para cada $\mathrm{mg} \mathrm{dm}^{-3}$ do nutriente aplicado. Diferentes pesquisadores verificaram esses resultados, como Prado et al. (2006), os quais verificaram incrementos crescentes a aplicação de doses de B $\left(0 ; 0,25 ; 0,5 ; 0,75 ;\right.$ e $\left.1,0 \mathrm{mg} \mathrm{dm}^{-3}\right)$ em Latossolo Vermelho distrófico; e Pegoraro et al. (2008), ao avaliarem três solos de diferentes texturas (arenosa, média e argilosa), também verificaram incrementos lineares nos teores de B em todos os solos ao aplicar doses desse nutriente $\left(0,3,6,9,12\right.$ e $\left.15 \mathrm{mg} \mathrm{dm}^{-3}\right)$.
No entanto, a falta de resposta à adubação boratada, conforme já comentado anteriormente, pode ser justificada pelos altos níveis de B no solo, uma vez que os teores de B (Figura 4a) estavam acima do nível crítico, que era de $0,5 \mathrm{mg} \mathrm{dm}^{-3}$ (Tecnologias de Produção de Soja - Região Central do Brasil 2012 e 2013, 2011). Moreira et al. (2010) também não obtiveram correlação significativa entre produção de matéria seca de soja e teor de B em Latossolo Vermelho eutroférrico de textura argilosa com teor inicial de $0,6 \mathrm{mg} \mathrm{dm}^{-3}$.

O teor de B no tecido foliar de soja aumentou linearmente com a aplicação desse nutriente (Figura 4a). Houve elevação na ordem de $43,7 \mathrm{mg} \mathrm{kg}^{-1}$ no teor de B para cada $\mathrm{mg} \mathrm{dm}^{-3}$ do nutriente aplicado. É interessante notar que, mesmo no tratamento sem $\mathrm{B}$, os teores do nutriente nas folhas encontravam-se acima da faixa considerada adequada para altas produtividades ( 25 a $55 \mathrm{mg} \mathrm{kg}^{-1}$ ), conforme apresentado por Rosolem (2007).

Rosolem et al. (2008) observaram resposta quadrática dos teores de $\mathrm{B}$ nas folhas da soja às doses do nutriente aplicado até a dose de $7,5 \mathrm{~kg} \mathrm{ha}^{-1}$. Os autores atribuíram este efeito em razão da lixiviação do elemento adicionado como adubo, que foi maior quanto maior a dose aplicada. Entretanto, Fageria (2000), avaliando cinco espécies vegetais em Latossolo Vermelho-Escuro do cerrado, encontrou toxidez de B para soja com a aplicação de $5,2 \mathrm{mg} \mathrm{kg}^{-1}$ e para o milho, de $5,7 \mathrm{mg} \mathrm{kg}^{-1}$ de B.

Foram observados neste estudo sintomas típicos de toxidez de $\mathrm{B}$ na dose máxima utilizada $\left(2 \mathrm{mg} \mathrm{dm}^{-3}\right)$ (Figura 5), em que os teores de $\mathrm{B}$ no tecido foliar da soja variaram de 135 a $176 \mathrm{mg} \mathrm{kg}^{-1}$, com média de $155 \mathrm{mg} \mathrm{kg}^{-1}$. Segundo Gupta (1979), a toxicidade de B nas plantas, em geral, ocorre quando o teor fica entre 98 e $257 \mathrm{mg} \mathrm{kg}^{-1}$, valores esses evidenciados neste trabalho. Furlani et al. (2001) constataram que os cultivares de soja começam a apresentar problemas de toxidez quando possuem teores acima de $83 \mathrm{mg} \mathrm{kg}^{-1}$.

De acordo com Mengel \& Kirkby (2001), por causa da imobilidade do B no floema sua translocação é quase que inexistente e, portanto, como seu teor é maior nas folhas mais velhas, os síntomas típicos de toxidez na soja se manifestam nas folhas mais velhas, conforme observado na figura 5 . O sintoma visual típico de toxidez de B na maioria das espécies é a queima das folhas, ou seja, clorose e necrose, frequentemente nas bordas e pontas das folhas mais velhas.

\section{CONCLUSÕES}

1. O desenvolvimento da cultura da soja não foi influenciado em solo com umidade até a tensão de $0,1 \mathrm{MPa}$, correspondendo ao teor de umidade de $65 \%$ da capacidade de campo. 
Quadro 5. Teor de B no solo e no tecido foliar soja em razão dos níveis de tensão de água no solo e das fontes e doses de boro aplicadas

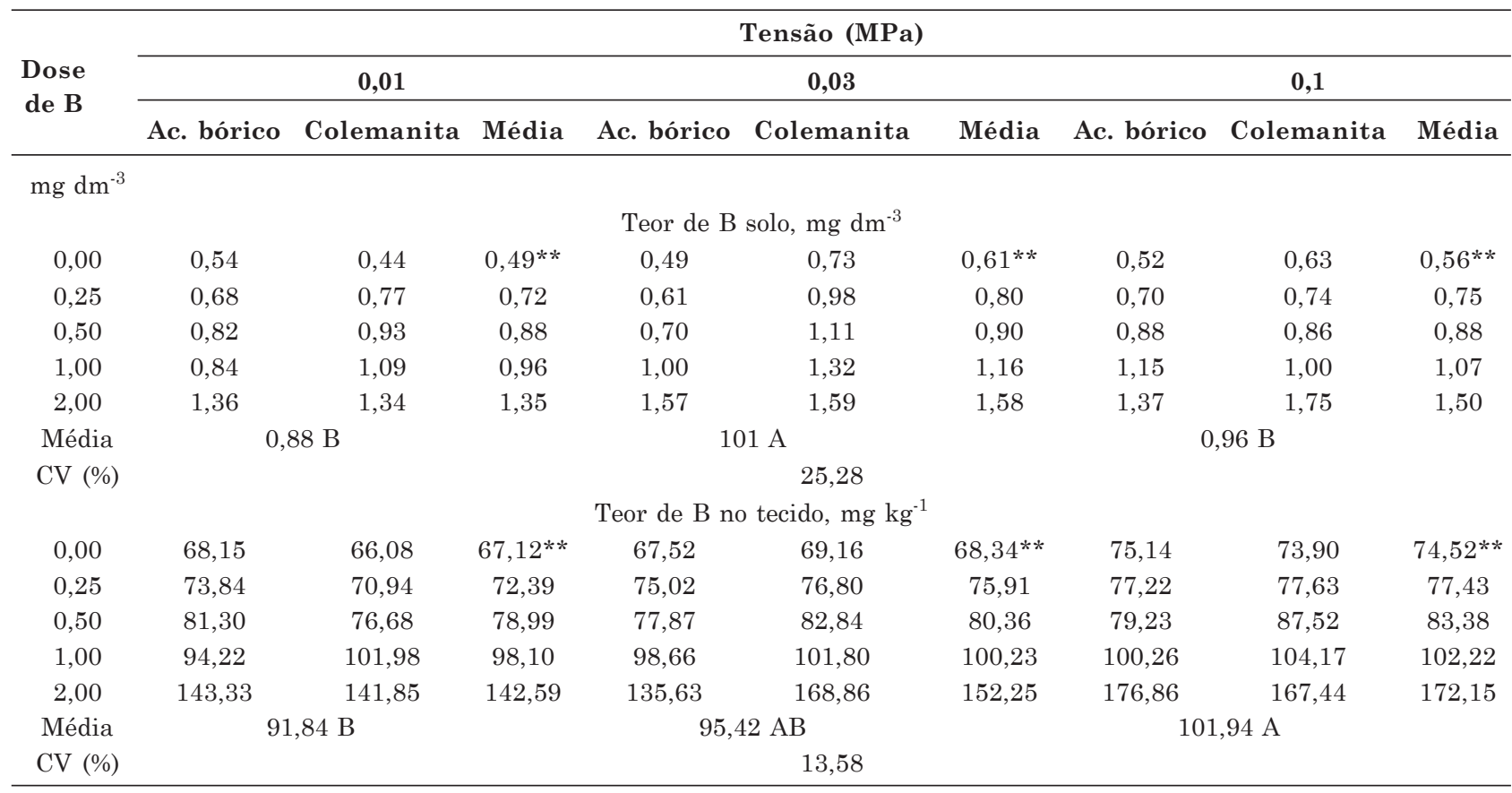

NS não significativo. Médias seguidas da mesma letra, maiúscula na linha e minúscula na coluna, não diferem entre si pelo teste de Tukey a $5 \%$.
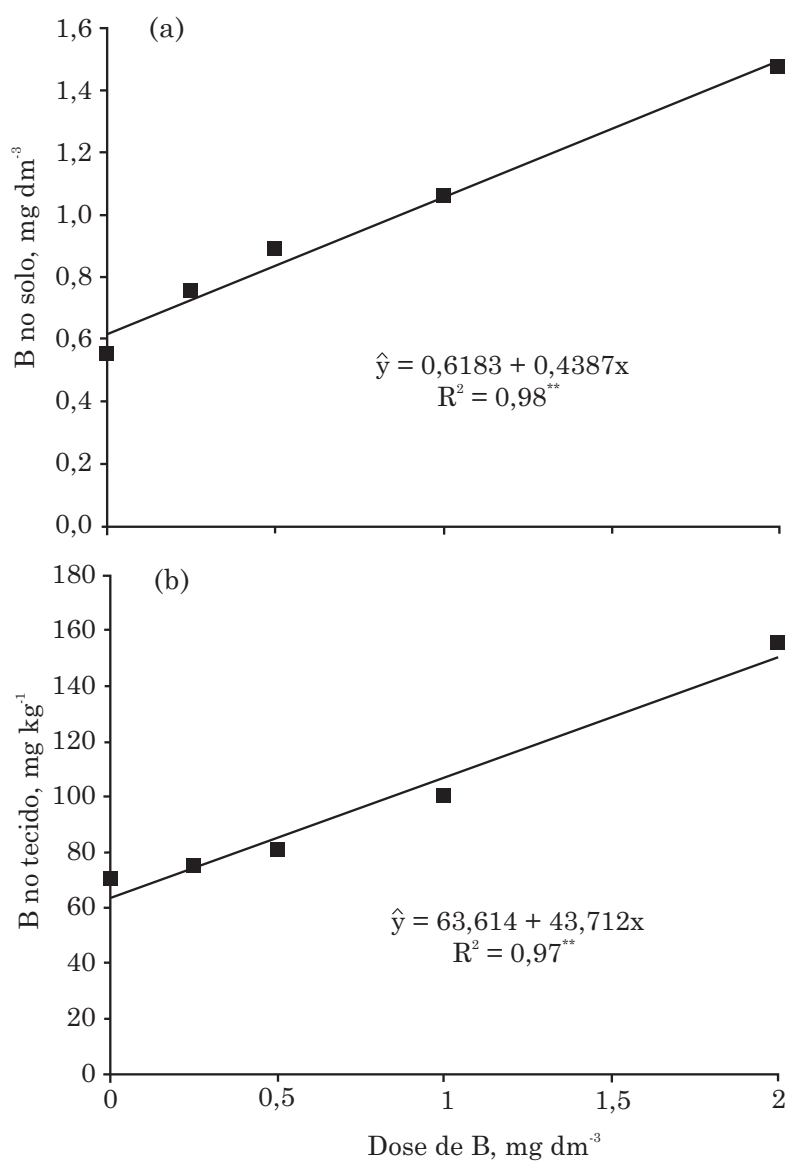

Figura 4. Teor de B no solo (a) e no tecido foliar da soja (b) em função das doses aplicadas ao solo.

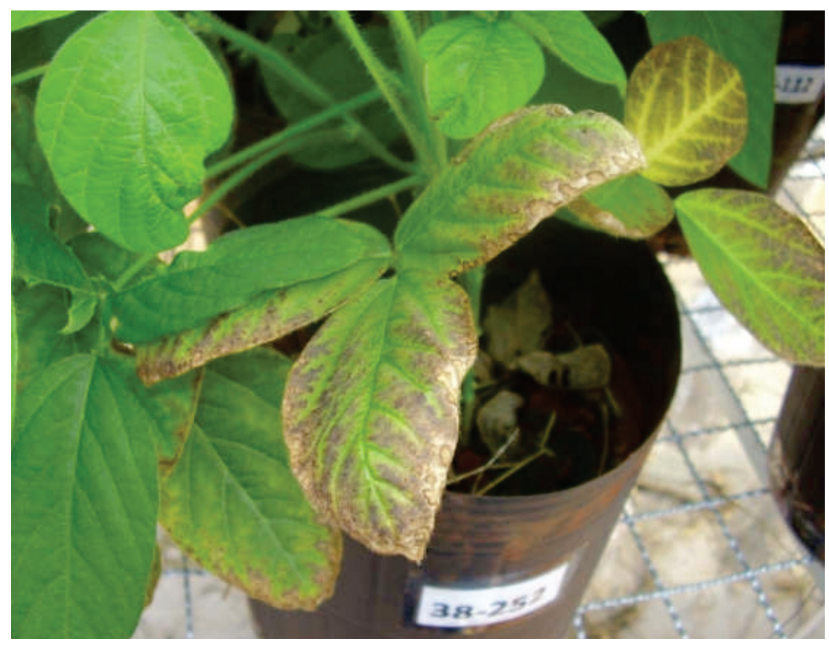

Figura 5. Sintomas de toxidez de B em plantas de soja cultivada em Latossolo Vermelho eutroférrico de textura arenosa com a aplicação de $2 \mathrm{mg} \mathrm{kg-1}$ desse nutriente.

2. O teor de água no solo até a tensão de - $0,1 \mathrm{MPa}$ não foi fator limitante para a absorção de B pela cultura da soja, em Latossolo Vermelho eutroférrico de textura arenosa com nível adequado desse nutriente.

3. A aplicação de doses crescentes de B até $2 \mathrm{mg} \mathrm{dm}^{-3}$, em Latossolo Vermelho eutroférrico de textura arenosa com teor inicial de $0,32 \mathrm{mg} \mathrm{dm}^{-3}$, interferiu negativamente no desenvolvimento do sistema radicular e não influenciou o desenvolvimento da parte aérea. 
4. A adubação com B proporcionou incremento crescente do teor relativo de água nas folhas, sob tensão de água no solo de $0,1 \mathrm{MPa}$.

\section{LITERATURA CITADA}

ABREU, C.A.; ABREU, M.F.; RAIJ, B.van; BATAGLIA, O.C. \& ANCRADE, J.C. Extraction of boron from soil by microwave heating for ICP-AES determination. Commun. Soil Sci. Plant Anal., 25:3321-3333, 1994.

BARRS, H.D. Effect of cycle variations in gas exchange under constant environmental conditions on the ratio of transpiration to net photosynthesis. Physiol. Plant., 21:918-929, 1968.

BATAGLIA, O.C. Análise química de plantas. In: FERREIRA, M.E. \& CRUZ, M.C.P., eds. Micronutrientes na agricultura. Piracicaba, Associação Brasileira para a Pesquisa da Potassa e do Fosfato, 1991. p.289-308.

BATAGLIA, O.C. Sistema de irrigação em vasos para experimentos de adubação. R. Bras. Ci. Solo, 13:81-86, 1989.

BONFIM-SILVA, E.M.; MONTEIRO, F.A. \& SILVA, T.J.A. Nitrogênio e enxofre na produção e no uso de água pelo capim-braquiária em degradação. R. Bras. Ci. Solo, 31:309$331,2007$.

BUZETTI, S.; MURAOKA, T. \& SÁ, M.E. Doses de boro na soja, em diferentes condições de acidez do solo: I. Produção de matéria seca e de grãos e nível crítico no solo. R. Bras. Ci. Solo, 14:157-161, 1990.

BYERS, D.E.; MIKKELSEN, R.L. \& COX, F.R. Greenhouse evaluation of four boron fertilizer material. J. Plant Nutr., 24:717-725, 2001.

CAKMAK, I. \& RÖMHELD, V. Boron deficiency-induced impairments of celular functions in plants. In: DELL, B.; ROWN, P.H. \& BELL, R.W., eds. Boron in soil and plants: Review. Symposium. Chiang Mai. Plant Soil, 193:71-83, 1998.

FAGERIA, N.K. Níveis adequados e tóxicos de boro na produção de arroz, feijão, milho, soja e trigo em solo de cerrado. R. Bras. Eng. Agric. Amb., 4:57-62, 2000.

FERREIRA, G.B.; FONTES, R.L.F.; FONTES, M.P.F. \& ALVAREZ V., V.H. Influência de algumas características do solo nos teores de boro disponível. R. Bras. Ci. Solo, 25:91-101, 2001.

FIOREZE, S.L.; PIVETTA, L.G.; FANO, A.; MACHADO, F.R. \& GUIMARÃES, V.F. Comportamento de genótipos de soja submetidos a déficit hídrico intenso em casa de vegetação. R. Ceres, 58:342-349, 2011.

FURLANI, A.M.C.; TANAKA, R.T.; TARALLO, M.; VERDIAL, M.F. \& MASCARENHAS, H.A.A. Exigência a boro em cultivares de soja. R. Bras. Ci. Solo, 25:929-937, 2001.

GALRÃO, E.Z. Effect of micronutrients and liming on the yield of soybeans grown in a lowland meadow soil. R. Bras. Ci. Solo, 14:381-384, 1990.
GHANATI, F.; MORITA, A. \& YOKOTA, H. Deposition of suberin in roots of soybean induced by excess boron. Plant Sci., 168:397-405, 2005.

GUPTA, U.C. Boron nutrition of crops. Adv. Agron., 31:373$377,1979$.

LIMA, J.C.P.S.; NASCIMENTO, C.W.A.; LIMA, J.G.C. \& LIRA JUNIOR, M.A.A. Níveis críticos e tóxicos de boro em solos de Pernambuco determinados em casa de vegetação. R. Bras. Ci. Solo, 31:73-79, 2007.

MALAVOLTA, E.; VITTI, G.C. \& OLIVEIRA, S.A. Avaliação do estado nutricional de plantas: Princípios e aplicações. 2.ed. Piracicaba: Potafos, 1997. 319p.

MATTOS, J.L.S.; GOMIDE, J.J. \& HUAMAN, C.A.M. Crescimento de espécies o gênero Brachiaria, sob déficit hídrico, em casa de vegetação. R. Bras. Zootec., 34:746-754, 2005.

MENGEL, K. \& KIRBY, E.A. Principles of plant nutrition. Bern: International Potash Institute, 2001. 687p.

MONTANHEIRO, M.N.; SAITO, S.N.T.; REICHARDT, K. \& LIBARDI, P.L. Controle de tensões de água no solo em vasos com feijoeiro (Phaseolus vulgaris). In: CONGRESSO BRASILEIRO DE CIÊNCIA DO SOLO, 17., Manaus, 1979. Anais... Campinas, Sociedade Brasileira de Ciência do Solo, 1979. p.68.

MORTVEDT, J.J. Needs for controlled-availability micronutrient fertilizers. Fert. Res., 38:213-221,1994.

MOREIRA. A.; CASTRO, C. \& OLIVEIRA, A.A. Produção, teor de boro e avaliação de extratores em solos cultivados com soja. Ci. Agrotec., 34:367-373, 2010.

MURPHY, L.S. \& WALSH, L.M. Fertilizer applications for correcting micronutrient deficiencies. In: MORTVEDT, J.J.; GIORDANO, P.M. \& INDSAY, W.L., eds. Micronutrients in agriculture. Madison, Soil Science Society of America, 1972. p.347-387.

NOVAIS, R.F.; NEVES, J.C.L. \& BARROS, N.F. Ensaio em ambiente controlado. In: OLIVEIRA, A.J.; GARRIDO, W.E.; ARAÚJO, J.D. \& LOURENÇO, S., eds. Método de pesquisa em fertilidade do solo. Brasilia, Embrapa-SEA, 1991. p.18-253.

PEGORARO, R.F.; SANTOS NETO, J.A.; SILVA, I.R.; FONTES, R.L.F.; FARIA, A.F. \& MOREIRA, F.F. Crescimento de soja em solos em resposta a doses de boro, calagem e textura do solo. Ci. Agrotec., 32:10921098, 2008.

PRADO, R.M.; NATALE, W. \& ROZANE, D.E. Níveis críticos de boro no solo e na planta para cultivo de mudas de maracujazeiro-amarelo. R. Bras. Frutic., 28:305-309, 2006.

RERKASEM, B.; BELL, R.W.; LODKAEW, S. \& LONERAGAN, J.F. Relationship of seed boron concentration to germination and growth of soybean (Glycine max). Nutr. Cycl. Agroecosyst., 48:217-223, 1997.

ROSOLEM, C.A. Produtividade máxima da soja. Rondonópolis, Fundação MT, 2007. p.237-244. (Boletim de Pesquisa de Soja)

ROSOLEM, C.A.; ZANCANARO, L. \& BÍSCARO, T. Boro disponível e resposta da soja em Latossolo Vermelho-Amarelo do Mato Grosso. R. Bras. Ci. Solo, 32:2375-2383, 2008. 
SHELP, B.J. Physiology and biochemistry of boron in plant. In: GUPTA, U.C., ed. Boron and its role in crop production. Boca Raton, CRC Press, 1993. p.53-85.

SRIVASTAVA, P.C. \& GUPTA, U.C. Trace elements in crop production. Oxford, IBH Publishing, 1996. 356p.

TAIZ, L. \& ZEIGER, E. Fisiologia vegetal. 3.ed. Porto Alegre, Artmed, 2004. 719p.
TECNOLOGIAS DE PRODUÇÃO DE SOJA - REGIÃO CENTRAL DO BRASIL 2012 e 2013. Londrina, Embrapa Soja, 2011. 261p.

UNIVERSIDADE FEDERAL DE VIÇOSA - UFV. Sistema para Análises Estatísticas e Genéticas - SAEG. Versão 8.0. Viçosa, MG, 1999.

WIKNER, B. Pretreatment of plant and soil samples. A problem in boron analysis: Part I. Plants. Commun. Soil Sci. Plant Anal., 17:1-25, 1986. 